\title{
O PROCESSO DE CONSTRUÇÃO DA SUCESSÃO EMPREENDEDORA EM EMPRESAS FAMILIARES: UM ESTUDO MULTICASO
}

\author{
Alex Fernando Borges ${ }^{1}$ \\ CEPPEAD - UFMG \\ Juvêncio Braga de Lima² \\ PPGAD - UFLA
}

Resumo: O objetivo desse trabalho é estudar o processo de sucessão em três empresas familiares. Para tanto, buscou-se elaborar uma vertente diferenciada para a apreensão desse processo, a partir de uma construção teórica envolvendo os campos de estudos sobre empresas familiares e sobre empreendedorismo. Esta vertente, chamada aqui de sucessão empreendedora, consiste em um processo socialmente construído e dialético, resultante da interação entre predecessores e sucessores no âmbito de uma empresa familiar, e envolve a manifestação de ações intraempreendedoras no decorrer desses processos sucessórios. Os estudos de caso, realizados por meio de entrevistas com predecessores e sucessores, revelaram a possibilidade de apreensão do processo de sucessão empreendedora, verificando-se como aspectos tais como a aceitabilidade, a credibilidade e a legitimidade contribuíram para a construção da liderança dos sucessores. A partir dessa liderança, os sucessores praticariam ações intraempreendedoras, sobretudo em termos de inovação e criação de valor, conduzindo a empresa familiar ao crescimento e competitividade. Não obstante, o surgimento de conflitos familiares e de resistências às mudanças efetuadas pelos sucessores abre possibilidade para a identificação de situações em que não se verifica a sucessão ou não se verifica o intraempreendedorismo, e assim conduzindo a uma reconstrução mais ampla da noção de sucessão empreendedora. Portanto, a construção teórica resultante deste estudo revela o potencial que a noção de sucessão empreendedora assume para a apreensão de dimensões pouco exploradas no campo de estudos sobre empresas familiares.

Palavras-chave: Sucessão, empresa familiar, empreendedorismo.

\section{THE CONSTRUCTION PROCESS OF ENTREPRENEURIAL SUCCESSION IN FAMILY BUSINESS: A MULTICASE STUDY}

\begin{abstract}
The purpose of this paper is to study the succession process in three family businesses. A different approach for this process was elaborated from a theoretical construction involving the fields of entrepreneurship and family business research. This approach, named here as entrepreneurial succession, consists in a dialectic, socially constructed process, resultant from the interaction between predecessors and successors within family firms, and involves the manifestation of intra-entrepreneurial actions in succession processes. The cases studied, operationalized through interviews with predecessors and successors, revealed the

\footnotetext{
${ }^{1}$ Universidade Federal de Uberlândia, Faculdade de Ciências Integradas do Pontal, Rua 20, n. 1600. Bairro Tupã. Ituiutaba - MG, CEP 38304-402.

${ }^{2}$ FUMEC, Av. Afonso Pena, 3080, Belo Horizonte - MG, CEP: 30.130-009.
} 
possibility of apprehending the entrepreneurial succession process, verifying how aspects such as acceptability, credibility, and legitimacy, contributed to successors' leadership. From this leadership, successors implemented intra-entrepreneurial actions, such as innovation and value creation, leading the family firm to growth and competitiveness. Nevertheless, the emergence of family conflict and resistance to changes made by successors creates possibilities to identify situations in which succession and intrapreneurship are not verified, and thus conducting to a broader reconstruction of the entrepreneurial succession concept. Therefore, the theoretical construction resultant from this study reveals the potential that entrepreneurial succession notion assumes to the apprehension of dimensions few explored on the field of family business research.

Keywords: Succession, family business, entrepreneurship.

\section{INTRODUÇÃO}

O objetivo deste trabalho consiste em estudar a construção e a evolução do processo de sucessão em empresas familiares situadas no estado de Minas Gerais. Para tanto, buscou-se elaborar uma vertente diferenciada para a apreensão do processo de sucessão, a da sucessão empreendedora, a partir de uma construção teórica envolvendo elementos presentes no campo de estudos sobre empreendedorismo e no campo de estudos sobre empresas familiares.

A construção de relações teóricas entre empreendedorismo e empresas familiares tem sido explorada em pesquisas recentes. Essas pesquisas trouxeram articulações entre teorias específicas a cada um dos campos, com o intuito de obter uma melhor compreensão de possíveis interrelações existentes. Ao valorizar essa interação, emerge uma direção de pesquisas conhecida como empreendedorismo familiar, permitindo a análise de interações entre família e empresa (HECK et al., 2006; HECK et al., 2008; HECK; MISHRA, 2008).

Com isso, tornar-se-ia possível a verificação do fenômeno do empreendedorismo em empresas familiares. Neste trabalho, esse movimento é efetuado a partir da análise do processo de sucessão, buscando identificar elementos que possam ser associados ao intraempreendedorismo. Por exemplo, Dyer Junior e Handler (1994) relatam que, com o advento da sucessão, deve-se questionar se a geração sucessora seria capaz de manter o espírito empreendedor do fundador e/ou oferecer novas ideias para a empresa no decorrer desses processos. Para Fletcher (2004), existe necessidade de se analisar a interação entre os domínios do empreendedorismo e de empresas familiares, a partir da (re)emergência organizacional e da problemática da sucessão, permitindo a 
verificação da presença da ação empreendedora em processos sucessórios. Assim, o empreendedorismo se apresenta como elemento em potencial que pode sustentar o sucesso e a sobrevivência de empresas familiares ao longo de suas gerações futuras (KELLERMANNS; EDDLESTON, 2006).

$\mathrm{Na}$ medida em que os sucessores agem de forma empreendedora, surgem elementos que podem ser associados ao fenômeno do intraempreendedorismo, ou seja, a ações empreendedoras que ocorrem no âmbito de uma organização já estabelecida. Assim, o intraempreendedorismo se manifesta por meio de ações intraempreendedoras de sucessores, as quais podem contribuir para a efetividade do processo sucessório e para a sobrevivência futura da organização. Ao inserir-se de modo proativo em mudanças nas empresas, os sucessores, em interação com predecessores, tornam-se agentes da construção de um processo de sucessão empreendedora. Tratar-se-ia, pois, de um processo socialmente construído, tendo como pano de fundo suas relações internas e externas com membros da família, da empresa e demais agentes do ambiente de negócios. A construção teórica resultante deste estudo revela o potencial que a noção de sucessão empreendedora assume para a apreensão de dimensões pouco estudadas no campo de estudos sobre empresas familiares.

\section{A CONSTRUÇÃO DO PROCESSO DE SUCESSÃO EMPREENDEDORA EM EMPRESAS FAMILIARES}

As empresas familiares tornam-se objeto de problematização científica, na medida em que são discutidos elementos centrais associados à natureza desse tipo de organização. A problematização das empresas familiares, enquanto objetos de estudo, envolvem aspectos tais como sua definição conceitual, a identificação de fontes de distinção frente às organizações não familiares e as particularidades associadas à dinâmica da interação entre família e empresa (SHARMA, 2006).

Verifica-se a existência de uma variedade de conceitos voltados para explicar o significado do termo empresa familiar, tornando a definição desses objetos confusa e limitada. Neste sentido, diferentes pesquisadores têm procurado estabelecer uma definição mais completa para o termo empresa familiar, associando a perspectiva do processo de sucessão.

Neste trabalho, compreende-se como empresa familiar aquela perfeitamente identificada com uma família a pelo menos duas geração, sendo caracterizada 
quando esta ligação implica em uma relação recíproca entre a estratégia e a gestão da organização, e os interesses e objetivos da família empresária (DONNELLEY, 1964). Assim, verifica-se a inclusão da sucessão como elemento central para a definição de empresa familiar, ressaltando-se a necessidade de permanência da família por, pelo menos, duas gerações para que a empresa possa ser considerada como familiar.

A perspectiva do processo de sucessão assume um papel central em muitos estudos que buscam investigar a natureza e as especificidades das empresas familiares. Na medida em que se visualiza analiticamente o campo de estudos sobre empresas familiares, é possível observar que a sucessão tem sido a temática mais estudada ao longo dos últimos anos (MELO et al., 2008; DEBICKI, et al., 2009). A sucessão vem sendo pesquisada mediante abordagens variadas, a partir de um quadro caracterizado pela coexistência de diversos campos de análise. Entretanto, existem problemáticas que não foram adequadamente estudadas, revelando falhas de diferentes construtos ao abordar o processo sucessório em empresas familiares (BROCKHAUS, 2004). Assim, apesar de ser o principal foco de estudos e pesquisas sobre empresas familiares, a sucessão ainda representa um desafio no campo da interpretação e da modelização (BORGES et al., 2008).

Brockhaus (2004) destaca que a sucessão é um momento significativo no ciclo de vida da empresa familiar, na medida em que influi sobre a própria sobrevivência da organização: de um lado, esse processo pode impulsionar o crescimento da organização, a partir da inserção de novas práticas de gestão e novos direcionamentos estratégicos (TILLMANN; GRZYBOVSKI, 2005); por outro, pode determinar a falência da empresa familiar, a partir do surgimento de conflitos inerentes à dinâmica entre família e empresa (HAVEMAN; KHAIRE, 2004). Desse modo, é a forma como ocorre o processo de sucessão que influencia a possibilidade de continuidade futura da empresa familiar (GRZYBOVSKI et al., 2008).

O processo de sucessão envolve o desejo de sobrevivência da empresa, a busca pela manutenção da organização sob o controle da família e à possibilidade de a geração sucessora dar continuidade ao projeto familiar (SHARMA, 2006). A partir disso, surgem elementos que influem sobre a efetividade do processo: a seleção, o treinamento, a formação educacional e profissional, e o desenvolvimento de sucessores no âmbito da organização familiar, dentre outros (BROCKHAUS, 2004; IBRAHIM et al., 2004; SHARMA et al., 1997). 
Ao mesmo tempo, tais elementos influem na inserção dos sucessores na organização e contribuem para a socialização dos mesmos na empresa familiar. A socialização inicia-se em um período de atuação conjunta entre predecessores e sucessores, no qual é possível observar a presença de uma constante interação entre indivíduos, família e empresa (BORGES et al., 2008; LAMBRECHT, 2005). Essa interação configura uma relação dialética, envolvendo dois elementos à natureza do processo de sucessão em empresas familiares: a transmissão da gestão e a transmissão do patrimônio (LIMA et al., 2007; BAYAD; BARBOT, 2002).

A transmissão gerencial constitui um processo que se inicia com a entrada do sucessor na empresa familiar. Para tanto, o sucessor deve dispor de capacidades empreendedoras e gerenciais suficientes para garantir o desenvolvimento das atividades, envolvendo a construção de elementos como sua aceitabilidade, credibilidade, legitimidade e liderança. Nessa perspectiva, a sucessão não apresenta uma evolução linear e sequencial, mas sim um processo dinâmico, configurado a partir de uma relação dialética que se constrói ao longo do tempo, por meio de um processo integrado em três dimensões: a empresa, o dirigente e o sucessor (BAYAD; BARBOT, 2002). Ao mesmo tempo, a transmissão gerencial traz em seu bojo a possibilidade de identificação de uma perspectiva contínua de transferência de empresas familiares para futuras gerações (BORGES et al., 2008; LAMBRECHT, 2005). A interação entre predecessores e sucessores assume um caráter central nesse processo, tanto em termos de condução conjunta dos negócios como para novos direcionamentos estabelecidos pela geração sucessora. Aceitabilidade, credibilidade e legitimidade se associam a uma perspectiva dinâmica, na medida em convergem para a aquisição da liderança dos sucessores. Essa liderança, por sua vez, pode se constituir como um elemento que contribui para a continuidade futura da organização, além de fornecer condições para a inserção de práticas inovadoras, colaborarando para renovações da empresa familiar (LIMA et al., 2007).

O fenômeno do intraempreendedorismo pode ser compreendido a partir da noção de ação empreendedora. De acordo com Lima (2008), essa perspectiva permite deslocar o foco da figura do empreendedor como um agente solitário de transformação de recursos em atividades produtivas, para criador de inovações, apresentando características especiais e diferenciadas em relação a outros agentes que porventura não tenham tido sucesso na criação, condução ou sustentabilidade de empreendimentos por eles conduzidos. Ainda segundo Lima (2008), se 
indivíduos agem de forma inovadora e obtêm sucesso no campo empresarial, podese afirmar que foram ações empreendedoras. Tais ações se verificam em um dado contexto e podem, igualmente, ser frutos de interações entre agentes voltados para um empreendimento comum. Assim, a ação empreendedora estaria vinculada a fatos, a decisão e ação de pequenos empresários, os quais poderiam ser simplesmente denominados de empreendedores por suas decisões e ações iniciais, seja ao criar e implantar uma empresa ou agirem de modo inovador em algum momento do ciclo de vida da organização (LIMA, 2008), o mesmo pode ser observado na prática de sucessores de empresas familiares.

Ao valorizar essa noção de ação empreendedora, a partir da possibilidade de intervenção em negócios já existentes, abre-se espaço para a noção de intraempreendedorismo. O conceito de intraempreendedorismo surge com a presença do fenômeno do empreendedorismo no interior de uma organização já existente, e abrange atividades e orientações inovadoras, tais como o desenvolvimento de novos produtos, serviços, tecnologia, técnicas administrativas e processos gerenciais, estratégias e posturas competitivas, que condicionam a organização a adotar novas direções (ANTONCIC; HISRICH, 2003; SHARMA; CHRISMAN, 1999).

Existem elementos que permitem verificar a possibilidade de manifestação do intraempreendedorismo em diferentes tipos de organizações. Dentre tais elementos, algumas aparecem como elementos centrais para a apreensão do fenômeno do intraempreendedorismo em organizações, tais como a inovação (GARTNER, 1990), criação de valor (GARTNER, 1990), crescimento (GARCIA et a.l, 2008) e competitividade (GARCIA et al., 1998). A partir dessas categorias, seria possível identificar a manifestação do fenômeno do intraempreendedorismo, abrindo caminho para uma compreensão mais aprofundada, permitindo, assim, uma análise sob a perspectiva do indivíduo e da organização influenciada por essa ação intraempreendedora.

A partir da interação entre empreendedorismo e empresas familiares, surge a possibilidade de construção de perspectivas diferenciadas, que permitem revelar e compreender a dinâmica de fenômenos que se manifestam no decorrer de processos de sucessão. Essas conexões teóricas, por sua vez, são articuladas a partir de duas vertentes: de um lado, analisa-se a problemática dos processos de sucessão em empresas familiares; de outro lado, investiga-se o fenômeno do 
empreendedorismo, assim como seus desdobramentos, em termos da vertente da ação empreendedora e do intraempreendedorismo (Quadro 1).

Quadro1 - Elementos da construção da sucessão empreendedora

\begin{tabular}{|c|c|}
\hline Elemento & Sucessão \\
\hline Aceitabilidade & $\begin{array}{l}\text { Envolve as experiências do sucessor no âmbito de sua família, sobretudo } \\
\text { durante a infância, sua instrução e formação, bem como experiências } \\
\text { adquiridas durante o período de atuação na empresa ao lado do fundador, } \\
\text { levando o sucessor a compartilhar da cultura e do ambiente da empresa familiar } \\
\text { (BAYAD; BARBOT, 2002). }\end{array}$ \\
\hline Credibilidade & $\begin{array}{l}\text { Envolve a delegação de responsabilidades para os sucessores e } 0 \\
\text { reconhecimento das competências (técnicas ou relacionais) dos sucessores, } \\
\text { que podem ser valorizadas a partir de suas experiências individuais (BAYAD; } \\
\text { BARBOT, 2002). }\end{array}$ \\
\hline Legitimidade & $\begin{array}{l}\text { A legitimidade é construída a partir do momento em que os sucessores } \\
\text { alcançam uma posição de poder, a confiar em sim mesmos e a ter a confiança } \\
\text { dos demais membros envolvidos na empresa (BAYAD; BARBOT, 2002). }\end{array}$ \\
\hline Liderança & $\begin{array}{l}\text { Envolve a perspectiva da autonomia, em que o sucessor começa a participar } \\
\text { gradativamente das atividades gerenciais, bem como a aprender o } \\
\text { funcionamento da organização sob uma perspectiva estratégica, garantindo a } \\
\text { manutenção futura da empresa familiar e o legado das antigas gerações } \\
\text { (BAYAD E BARBOT, 2002). }\end{array}$ \\
\hline Elemento & Intraempreendedorismo \\
\hline Inovação & $\begin{array}{l}\text { O ato de construir uma nova ideia, produto, serviço, mercado, tecnologia ou } \\
\text { processo organizacional, em uma organização nova ou já estabelecida } \\
\text { (GARTNER, 1990). }\end{array}$ \\
\hline $\begin{array}{l}\text { Criação de } \\
\text { Valor }\end{array}$ & $\begin{array}{l}\text { O ato de transformação e/ou criação de um novo negócio, gerar mudanças, } \\
\text { criar e crescer uma empresa, criar lucros, e romper com o status quo } \\
\text { (GARTNER, 1990). }\end{array}$ \\
\hline Crescimento & $\begin{array}{l}\text { Elementos associados para o crescimento da empresa, agregando a inovação e } \\
\text { a criação de valor, na medida em que proporcionam resultados que levam à } \\
\text { expansão e à renovação dessas empresas (GARCIA et al., 2008). }\end{array}$ \\
\hline Competitividade & $\begin{array}{l}\text { Com a inovação, a criação de valor e o crescimento, a organização passa a } \\
\text { atingir novos níveis de competitividade, a partir de uma preocupação com os } \\
\text { meios para se melhorar o posicionamento da empresa e com a construção de } \\
\text { ações que permitam o alcance de diferenciais e de vantagens competitivas } \\
\text { (GARCIA et al., 2008). }\end{array}$ \\
\hline
\end{tabular}

Os aspectos envolvendo a sucessão em empresas familiares e o fenômeno do intraempreendedorismo podem ser vistos, quando observados no mesmo movimento, como suportes para a possibilidade de construção de processos de sucessão empreendedora. A sucessão empreendedora seria compreendida como um processo socialmente construído e dialético, resultante da interação entre predecessores e sucessores em uma empresa familiar e da manifestação de elementos associados à sucessão e ao intraempreendedorismo. Configurando-se a sucessão empreendedora, abrem-se possibilidades que influenciariam de modo significativo as perspectivas de continuidade e renovação de empresas familiares no decorrer e após a construção desses processos (Figura 1). 
Figura 1 - Processo de sucessão empreendedora em empresas familiares

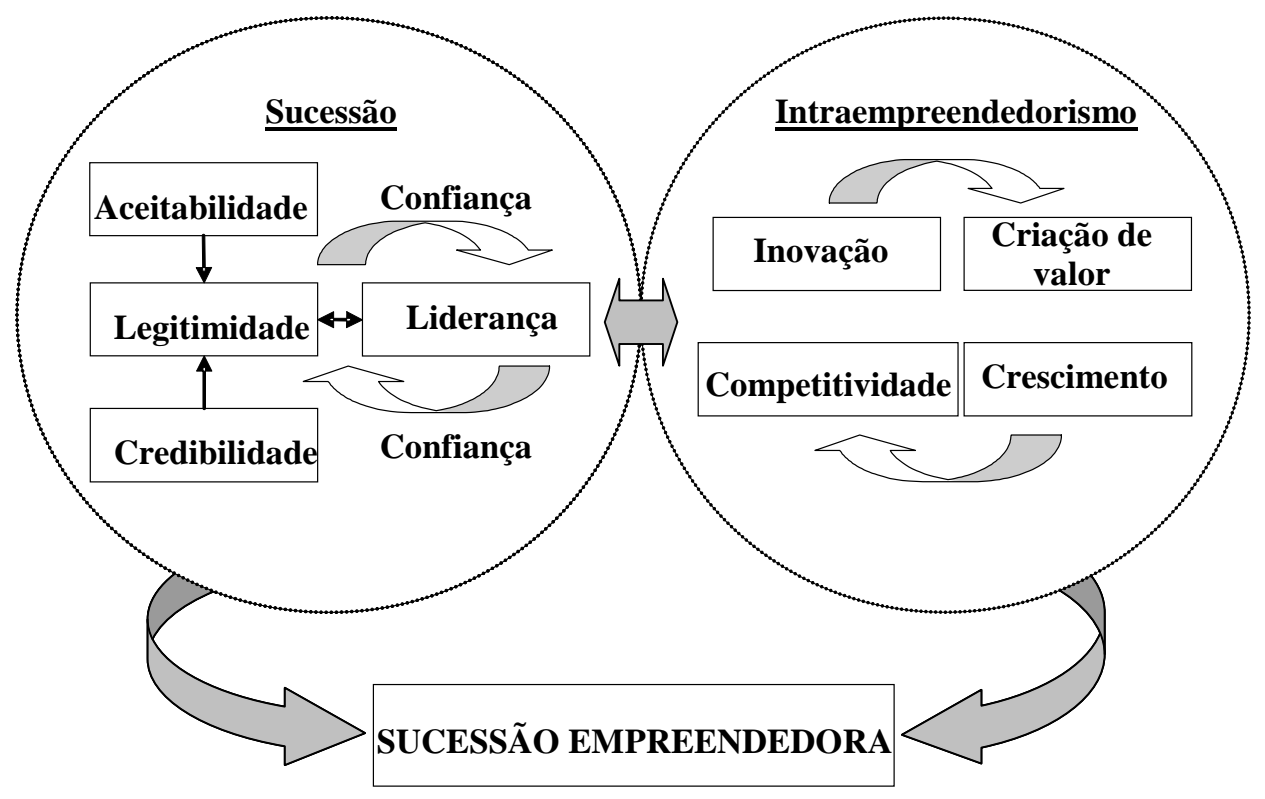

\section{METODOLOGIA}

Neste trabalho, foi efetuada uma pesquisa qualitativa (CRESWELL, 2007; GODOI; BALSINI, 2006) voltada para compreender a construção e a evolução de processos de sucessão empreendedora em empresas familiares. A pesquisa qualitativa consiste no método mais adequado para apreender a dinâmica das empresas familiares, devido ao seu caráter circular e reflexivo (DAVEL; COLBARI, 2003; DAVEL; COLBARI, 2000), e a seu caráter epistemológico subjetivista. Ao estabelecer esse caráter subjetivista como pano de fundo, parte-se do pressuposto que a realidade é socialmente construída (BERGER; LUCKMANN, 2005), e o pesquisador pode interpretar e construir a realidade a partir de suas análises, incluindo aí o ambiente organizacional (CARRIERI et al., 2008).

Para tanto, foi realizado um estudo multicaso (GODOY, 2006; YIN, 2005). Para Davel e Colbari (2003), a estratégia de estudo de caso, quando aplicada ao estudo de organizações familiares, permite avaliar uma situação que abrange família e empresa em seu contexto original e analisar como essa interação se manifesta e evolui ao longo do tempo. Dessa forma, esses fatores tornam-se essenciais para 
compreender processos que ocorrem no âmbito de empresas familiares, associados à problemática da sucessão (LAMBRECHT, 2005).

Foram estudadas três empresas familiares situadas em diferentes cidades da região Sul de Minas Gerais. O critério para seleção dos casos foi estabelecido a partir da necessidade de verificação de processos de sucessão envolvendo a interação entre, pelo menos, duas diferentes gerações da família empresária. Os nomes das empresas e dos entrevistados foram suprimidos, de modo a resguardar a privacidade das informações levantadas. Como técnicas de coleta de dados, foram utilizadas entrevistas em profundidade, orientadas por meio de um roteiro semiestruturado (GODOI; MATTOS, 2006; ROESCH, 2006).

Foram feitas entrevistas com os fundadores (quando possível), predecessores atuantes nas empresas e seus respectivos sucessores. Tais entrevistas foram gravadas e transcritas, de modo que pudessem ser recuperadas e analisadas conforme a orientação teórica proposta e os objetivos da pesquisa. Adotou-se como instrumento a técnica de análise de conteúdo (BARDIN, 2004; MATTOS, 2006). Isso permitiu que os elementos associados aos processos de sucessão e ao intraempreendedorismo fossem recuperados, a partir da orientação das categorias teóricas estabelecidas na noção de sucessão empreendedora, mas abrindo possibilidade para o surgimento de elementos não previstos anteriormente, destacando o caráter de provisoriedade da proposta teórico-metodológica da pesquisa.

\subsection{CONSTRUÇÃO DO PROCESSO DE SUCESSÃO EMPREENDEDORA NAS EMPRESAS FAMILIARES ESTUDADAS}

Nesta seção, são apresentados os resultados da pesquisa, resgatando-se, primeiramente, as trajetórias históricas das empresas familiares estudadas.

A empresa do setor joalheiro (Caso 1) tem 31 anos de atuação no ramo de joalheria, relojoaria e ótica. A sucessão iniciou-se em 1991, com a entrada das filhas do fundador. Atualmente, a administração da empresa é compartilhada por membros da primeira e da segunda geração da família empresária, sendo o fundador e duas filhas sucessoras responsáveis por funções estratégicas e gerenciais na matriz da empresa.

A empresa do setor farmacêutico (Caso 2) existehá 43 anos. A primeira sucessão iniciou-se com a fundação da empresa familiar e os sucessores, 
fortemente incentivada pelo fundador. Posteriormente, em 1991, iniciou-se a segunda sucessão, com a entrada de um neto do fundador. Posteriormente, em 2005, outro neto do fundador começou a atuar na empresa familiar. Outro fator de destaque se refere à morte do fundador, ocorrida no ano de 2006. Atualmente, a organização é gerenciada por membros da segunda e da terceira geração da família empresária, sendo filho, nora e netos do fundador os responsáveis pela condução dos negócios nas diferentes unidades da empresa.

A empresa do setor de materiais de construção (Caso 3) tem 80 anos. A primeira sucessão ocorreu no ano de 1950, tendo o fundador (falecido em 1973) convidado um genro para auxiliá-lo nas atividades da empresa. A segunda sucessão deu-se de forma semelhante, com a entrada de um genro desse sucessor para auxiliá-lo na condução dos negócios (1974). Com a morte deste predecessor, no ano de 1990, ocorreu a entrada de uma de suas filhas, neta do fundador. A terceira sucessão iniciou-se no ano de 2003, com a entrada de um sucessor e uma sucessora. Atualmente, a organização é administrada por membros da terceira e quarta geração da família empresária, constituindo uma sociedade entre, de um lado, uma neta do fundador e sua filha, e de outro um dirigente casado com outra neta do fundador e seu filho.

A construção de processos de sucessão, nas empresas familiares estudadas envolveu a transmissão dessas organizações mediante diferentes gerações das famílias empresárias.

De um lado, a aceitabilidade foi construída na medida em que os sucessores vivenciaram um período de socialização, no qual atuaram em diferentes áreas das empresas estudadas. Os sucessores tiveram a oportunidade de aprender o funcionamento das respectivas empresas, partilhando de sua cultura e de seu ambiente. De outro lado, a credibilidade caracterizou-se quando os sucessores passaram a aprender com as experiências adquiridas e a acumular conhecimentos acerca das atividades que desempenhavam. Esse conjunto de práticas contribuiu para o desenvolvimento de habilidades e competências, que, uma vez adquiridas pelos sucessores, passaram a ser reconhecidas pelos predecessores.

A legitimidade se configurou a partir das relações de confiança existentes entre fundadores e/ou predecessores e seus sucessores, caracterizada por uma relação de respeito mútuo entre os membros das diferentes famílias empresárias. Com isso, os sucessores passaram a acumular maiores responsabilidades e a se 
tornar responsáveis, juntamente com os predecessores, pela condução efetiva dos negócios das empresas familiares estudadas.

A construção da liderança dos sucessores esteve atrelada à perspectiva da autonomia. Com o tempo, os sucessores foram adquirindo autonomia para atuar de forma estratégica na organização. Adicionalmente, nos casos estudados, havia uma expectativa de que os sucessores tivessem capacidade para dar continuidade à empresa, garantindo a manutenção do legado e do projeto instituído pelas gerações predecessoras da família empresária (Quadro 2).

Quadro 2 - Elementos do processo de sucessão

\begin{tabular}{|c|c|c|c|}
\hline Elemento & Caso 1 & Caso 2 & Caso 3 \\
\hline Aceitabilidade & $\begin{array}{l}\text { Elas começaram com 11, } \\
12 \text { anos, na função mais } \\
\text { humilde, mais simples, } \\
\text { como todo mundo. } \\
\text { Começa a fazer } \\
\text { trabalhos secundários } \\
\text { qualquer, vai aprendendo } \\
\text { e depois, quando } \\
\text { demonstrar competência, } \\
\text { é que vai sendo } \\
\text { aproveitado, não é nem } \\
\text { promovido, vai sendo } \\
\text { aproveitado em certas } \\
\text { atividades mais } \\
\text { essenciais (Fundador, } \\
\text { Entrevista 2). }\end{array}$ & $\begin{array}{l}\text { (...) nós começamos a } \\
\text { entrar e a trabalhar com } \\
\text { meu pai. No começo, ele } \\
\text { foi ensinando e a gente } \\
\text { aprendendo a fazer um } \\
\text { atendimento, vender um } \\
\text { remédio, aprendendo } \\
\text { aquelas coisas que faziam } \\
\text { parte do dia-a-dia da } \\
\text { farmácia mesmo } \\
\text { (Predecessor, Entrevista } \\
\text { 4). }\end{array}$ & $\begin{array}{l}\text { Olha, minha entrada } \\
\text { aqui foi o seguinte. Eu } \\
\text { morava em Belo } \\
\text { Horizonte, estudava lá. } \\
\text { Aí eu resolvi fazer } \\
\text { Administração (...). Aí } \\
\text { minha mãe me chamou } \\
\text { pra trabalhar com ela } \\
\text { (...). Aí eu comecei a } \\
\text { trabalhar na [empresa], } \\
\text { tentando me encaixar } \\
\text { em alguma coisa que eu } \\
\text { fosse útil. Aí eu girei a } \\
\text { empresa toda, trabalhei } \\
\text { com quase tudo que } \\
\text { você imaginar (...) e fui } \\
\text { vendo a complexidade } \\
\text { que era essa empresa } \\
\text { (Sucessora, Entrevista } \\
\text { 12). }\end{array}$ \\
\hline Credibilidade & $\begin{array}{l}\text { A [filha mais velha] cuida } \\
\text { da produção. Ela } \\
\text { entende muito de joias, } \\
\text { ela entende de mercado. } \\
\text { Ela sabe muito bem o } \\
\text { que comprar, relógios, } \\
\text { produtos, que marca } \\
\text { comprar, fica atenta para } \\
\text { o que está na moda. Ela } \\
\text { entende de vitrinista, ela } \\
\text { sabe expor produto, ela } \\
\text { estuda em cima disto. } \\
\text { (...) Ao nível de gestão a } \\
\text { [filha mais nova] é uma } \\
\text { pessoa superfocada, (...) } \\
\text { ela fez Administração e } \\
\text { ela cuida da parte } \\
\text { administrativa da } \\
\text { empresa. Ela cuida da } \\
\text { gestão financeira, cuida } \\
\text { do fluxo de recursos, } \\
\text { ajuda no investimento } \\
\text { desses recursos (...), é }\end{array}$ & $\begin{array}{l}\text { (...) Depois, a gente foi } \\
\text { pegando experiência com } \\
\text { ele, eu fui aprendendo a } \\
\text { administrar a farmácia e } \\
\text { ele foi delegando as } \\
\text { coisas pra gente } \\
\text { (Predecessor, Entrevista } \\
\text { 4). }\end{array}$ & $\begin{array}{l}\text { (...) Fui pegando o jeito, } \\
\text { aprendendo como as } \\
\text { coisas funcionavam e } \\
\text { logo comecei a ganhar } \\
\text { autonomia e a ajudar ele } \\
\text { a administrar a loja... } \\
\text { (Predecessor, Entrevista } \\
\text { 8). } \\
\text { Com o tempo, eu (...) } \\
\text { comecei a trabalhar pra } \\
\text { valer. E isso foi bom } \\
\text { porque eu me senti útil, } \\
\text { tava fazendo algo que } \\
\text { não tinha e o meu tio e a } \\
\text { minha mãe começaram } \\
\text { a ver a importância disso } \\
\text { pra empresa } \\
\text { (Sucessora, Entrevista } \\
\text { 12). }\end{array}$ \\
\hline
\end{tabular}




\begin{tabular}{|c|c|c|c|}
\hline & $\begin{array}{l}\text { responsável pela } \\
\text { contratação de novos } \\
\text { colaboradores, ela é } \\
\text { responsável pelo } \\
\text { treinamento. (...) Então, } \\
\text { há uma contribuição } \\
\text { diuturna das filhas na } \\
\text { empresa... (Fundador, } \\
\text { Entrevista 2). }\end{array}$ & & \\
\hline Legitimidade & $\begin{array}{l}\text { Com o passar do tempo, } \\
\text { eu fui adquirindo mais } \\
\text { experiências, eu fui } \\
\text { tendo, assim..., } \\
\text { ganhando autonomia } \\
\text { para trabalhar, e isso eu } \\
\text { acredito que seja a } \\
\text { marca registrada do } \\
\text { nosso trabalho: a } \\
\text { confiança que a gente } \\
\text { adquire para desenvolver } \\
\text { os trabalhos. Eu acho } \\
\text { que é basicamente isso, } \\
\text { fruto da experiência } \\
\text { (Sucessora, Entrevista } \\
\text { 3). }\end{array}$ & $\begin{array}{l}\text { (...) Eu fui aprendendo por } \\
\text { experiência mesmo, com o } \\
\text { convívio com meu pai e } \\
\text { com a minha mãe. E aí fui } \\
\text { pegando o jeito e fui } \\
\text { pegando cada vez mais } \\
\text { serviço. Hoje, a gente tem } \\
\text { uma atuação boa, a gente } \\
\text { ajuda a dirigir a empresa e } \\
\text { já responde por quase } \\
\text { tudo. Pra você ter uma } \\
\text { ideia, hoje, meu pai viaja, } \\
\text { minha mãe viaja, tudo fica } \\
\text { na minha mão, na mão do } \\
\text { meu irmão. (...) [O } \\
\text { relacionamento] entre eu, } \\
\text { meu pai, minha mãe e } \\
\text { meu irmão é muito } \\
\text { tranquilo. Um ouve o } \\
\text { outro, troca ideia e tudo } \\
\text { mais (Sucessor } 1 \text {, } \\
\text { Entrevista 6). }\end{array}$ & $\begin{array}{l}\text { [Os sucessores] já estão } \\
\text { entrando nos trilhos. A } \\
\text { gente vai dando } \\
\text { autonomia pra eles, vai } \\
\text { dando responsabilidade } \\
\text { e eles correspondem } \\
\text { bem, o que traz pra } \\
\text { gente uma confiança } \\
\text { muito boa. Eles vão } \\
\text { pegando cada vez mais } \\
\text { experiência, que eu acho } \\
\text { que isso aí é muito } \\
\text { importante. Hoje, se } \\
\text { você parar pra pensar, a } \\
\text { presença deles é } \\
\text { importantíssima, dá } \\
\text { tranquilidade pra gente. } \\
\text { Na nossa ausência, você } \\
\text { vê que tem uma } \\
\text { retaguarda. Quando } \\
\text { você sai, tem um deles, } \\
\text { você fica muito mais } \\
\text { tranquilo (Predecessor, } \\
\text { Entrevista 8). }\end{array}$ \\
\hline Liderança & $\begin{array}{l}\text { (...) Eu passei a } \\
\text { acumular outras funções } \\
\text { e responsabilidades } \\
\text { maiores. Então, existem } \\
\text { decisões a serem } \\
\text { tomadas que partem de } \\
\text { mim, decisões mais } \\
\text { importantes que estão } \\
\text { sob a minha } \\
\text { responsabilidade agora } \\
\text { (...) e essa autonomia se } \\
\text { deu com o ganho de } \\
\text { responsabilidades e com } \\
\text { a maturidade profissional } \\
\text { (Sucessora, Entrevista } \\
\text { 3). } \\
\end{array}$ & $\begin{array}{l}\text { Meu pai tinha uma visão } \\
\text { muito de farmácia, de } \\
\text { atendimento, uma coisa } \\
\text { mais restrita. Já eu tenho } \\
\text { uma visão muito mais } \\
\text { comercial. Então, no } \\
\text { momento em que ele foi } \\
\text { me dando autonomia, eu } \\
\text { fui ficando cada vez mais } \\
\text { responsável por } \\
\text { administrar a farmácia e, } \\
\text { aí, houve uma modificação } \\
\text { muito grande... } \\
\text { (Predecessor, Entrevista } \\
\text { 4). }\end{array}$ & $\begin{array}{l}\text { (...) Eu fui assumindo } \\
\text { responsabilidades e } \\
\text { ajudando o meu sogro. } \\
\text { Virei um dirigente } \\
\text { mesmo, tendo } \\
\text { autonomia pra fazer as } \\
\text { coisas e, com isso, ser } \\
\text { responsável também por } \\
\text { crescer a empresa e } \\
\text { pela sobrevivência da } \\
\text { [empresa] mesmo } \\
\text { (Predecessor, Entrevista } \\
\text { 8). }\end{array}$ \\
\hline
\end{tabular}

Paralelamente à construção de processos de sucessão, constatou-se o desencadeamento de uma série de ações voltadas para a melhoria das empresas familiares estudadas, revelando a manifestação do intraempreendedorismo.

De um lado, a inovação configurou-se na medida em que os sucessores buscaram construir ações visando à criação e adoção de novas atividades e práticas 
organizacionais, voltadas para 0 incremento da gestão e para novos direcionamentos estratégicos. De outro lado, a criação de valor se deu por meio da abertura de novas unidades das empresas familiares. A criação de valor foi construída a partir da interação com a geração predecessora e com a participação dos sucessores nesses processos de concepção. Como resultado, a criação de valor pôde permitir uma ampliação da área de atuação das empresas e da capacidade de atendimento a novos mercados e setores, contribuindo para a expansão das atividades das organizações familiares estudadas.

Os aspectos vinculados à inovação e à criação de valor, bem como ao aproveitamento dos resultados de tais ações, contribuíram para o crescimento das empresas. Ao mesmo tempo, esse crescimento assumiu uma convergência para a construção da competitividade, na medida em que permitiu às empresas estudadas alcançar a liderança de seu setor de atuação, conquistada a partir de uma preocupação com meios para melhorar o posicionamento da empresa no mercado e com a construção de ações que possibilitem o alcance de diferenciais e vantagens competitivas (Quadro 3).

Quadro 3 - Elementos do intraempreendedorismo

\begin{tabular}{|c|c|c|c|}
\hline Elemento & Caso 1 & Caso 2 & Caso 3 \\
\hline Inovação & $\begin{array}{l}\text { (...) Eu fiz muitas } \\
\text { melhorias. Eu implantei } \\
\text { um sistema pra fazer o } \\
\text { nosso controle } \\
\text { gerencial. Ele traz uma } \\
\text { série de indicadores } \\
\text { financeiros, uma série } \\
\text { de relatórios que } \\
\text { balizam as nossas } \\
\text { decisões, então, eu } \\
\text { pude mudar muito, eu } \\
\text { revolucionei o sistema } \\
\text { de indicadores e, hoje, } \\
\text { ele é feito de uma forma } \\
\text { muito mais simples, } \\
\text { muito mais objetiva. Eu } \\
\text { também participei da } \\
\text { implantação, junto com } \\
\text { o meu pai, do programa } \\
\text { de qualidade, que a } \\
\text { gente buscou colocar } \\
\text { pra melhorar } \\
\text { constantemente o nosso } \\
\text { trabalho. Também tem o } \\
\text { programa de } \\
\text { treinamentos, onde eu } \\
\text { não passo apenas as } \\
\text { questões de trabalho, } \\
\text { mas sim as questões }\end{array}$ & $\begin{array}{l}\text { Quando o [predecessor] } \\
\text { entrou, houve uma } \\
\text { revolução total. Inclusive, } \\
\text { no princípio, com o pai } \\
\text { dele, teve algumas } \\
\text { divergências porque, logo } \\
\text { que ele entrou, ele } \\
\text { comprou o primeiro } \\
\text { computador e tem uma } \\
\text { dificuldade da pessoa } \\
\text { mais antiga ter essa } \\
\text { aceitação. Mas o } \\
\text { [predecessor] foi } \\
\text { revolucionando tudo, } \\
\text { mudanças em todos os } \\
\text { aspectos, na forma de } \\
\text { como fazer as coisas, } \\
\text { mudou a mentalidade da } \\
\text { farmácia (Predecessora, } \\
\text { Entrevista 5). } \\
\\
\text { Depois que eu cheguei, eu } \\
\text { acho que mudou muita } \\
\text { coisa, mudou muito. A } \\
\text { farmácia deu uma } \\
\text { reviravolta na maneira de } \\
\text { agir, completamente. } \\
\text { Quando eu comecei, meu } \\
\text { pai já tinha ajeitado muita }\end{array}$ & $\begin{array}{l}\text { Olha, quando eu entrei, } \\
\text { eu quis colocar muita } \\
\text { coisa nova. A gente } \\
\text { tinha um esquema de } \\
\text { conta corrente daqueles } \\
\text { bem arcaicos. Já tinha } \\
\text { um computador, mas era } \\
\text { só pra nota fiscal e } \\
\text { controle de estoque. } \\
\text { Então, eu falei que isso } \\
\text { tava errado, porque } 90 \% \\
\text { das nossas vendas } \\
\text { 'tavam tudo em atraso e, } \\
\text { se a gente não desse } \\
\text { um jeito, a gente ia } \\
\text { acabar quebrando. (...) } \\
\text { Então, eu modernizei } \\
\text { isso daí, criei um } \\
\text { sistema pra controlar o } \\
\text { financeiro, (...) foi isso } \\
\text { que ajudou a salvar tudo } \\
\text { (Predecessora, } \\
\text { Entrevista 12). } \\
\text { A minha filha trouxe um } \\
\text { controle muito maior, um } \\
\text { acompanhamento muito } \\
\text { maior. Ela introduziu os } \\
\text { controles gerenciais }\end{array}$ \\
\hline
\end{tabular}




\begin{tabular}{|c|c|c|c|}
\hline & $\begin{array}{l}\text { das pessoas. Já a minha } \\
\text { irmã, mais ligada a essa } \\
\text { parte de produção, de } \\
\text { vendas, ela sempre 'tá } \\
\text { agregando novos } \\
\text { produtos, que você não } \\
\text { encontra em qualquer } \\
\text { lugar, relógios, joias, } \\
\text { acessórios, justamente } \\
\text { pra atender a esse } \\
\text { nosso mercado. Então, } \\
\text { a gente 'tá sempre } \\
\text { trazendo coisas novas } \\
\text { pra empresa... } \\
\text { (Sucessora, Entrevista } \\
\text { 3). }\end{array}$ & $\begin{array}{l}\text { coisa, mas era muito } \\
\text { amador ainda. Então, eu } \\
\text { procurei mudar a forma } \\
\text { como a empresa era } \\
\text { gerenciada, implantei } \\
\text { alguns sistemas pra } \\
\text { facilitar mesmo o trabalho, } \\
\text { os controles, a forma } \\
\text { como a gente trabalhava o } \\
\text { RH, funcionário, horário... } \\
\text { Eu acho que já evoluiu } \\
\text { muito, mas tem muito que } \\
\text { evoluir ainda (Sucessor 2, } \\
\text { Entrevista 7). }\end{array}$ & $\begin{array}{l}\text { nossos, pra gente saber } \\
\text { o quanto 'tá tendo de } \\
\text { lucro, pra gente controlar } \\
\text { mais e ter uma ideia de } \\
\text { como vão indo as } \\
\text { coisas. (...) Então houve } \\
\text { uma mudança muito } \\
\text { boa, porque a gente não } \\
\text { tinha esses números na } \\
\text { frente, em cima da } \\
\text { mesa, pra você } \\
\text { analisar... } \\
\text { (Predecessora, } \\
\text { Entrevista 10). }\end{array}$ \\
\hline $\begin{array}{l}\text { Criação de } \\
\text { valor }\end{array}$ & $\begin{array}{l}\text { (...) A gente discutiu a } \\
\text { possibilidade de } \\
\text { expansão dos negócios } \\
\text { e surgiu a ideia e a } \\
\text { oportunidade de abrir as } \\
\text { filiais. Foi uma decisão } \\
\text { em conjunto, } \\
\text { obviamente com a } \\
\text { liderança do meu pai, } \\
\text { mas que teve muito a } \\
\text { nossa participação, } \\
\text { ajudando muito desde o } \\
\text { início, dando ideias e } \\
\text { contribuições. E, com } \\
\text { isso, a gente pode abrir } \\
\text { essas duas lojas e a } \\
\text { gente tá muito satisfeito } \\
\text { com elas (Sucessora, } \\
\text { Entrevista 3). }\end{array}$ & $\begin{array}{l}\text { ós trabalhávamos em um } \\
\text { cômodo pequeno. Aí eu } \\
\text { comprei a loja da esquina, } \\
\text { ampliei, fiz o prédio, fui } \\
\text { crescendo. Aí eu comecei } \\
\text { partindo pra outras lojas. } \\
\text { (...) Depois [os filhos] me } \\
\text { ajudaram a abrir essas } \\
\text { lojas mais recentes } \\
\text { (Predecessor, Entrevista } \\
\text { 4). }\end{array}$ & $\begin{array}{l}\text { O principal objetivo } \\
\text { agora é essa rede, que } \\
\text { até surgiu de uma } \\
\text { sugestão do meu filho. } \\
\text { (...) Nós já estamos com } \\
19 \text { empresas formando } \\
\text { uma associação (...). No } \\
\text { momento, a gente 'tá } \\
\text { com uma central de } \\
\text { compras, mas (...) eu } \\
\text { penso que ela tem que } \\
\text { ser uma coisa mais } \\
\text { ampla, pra gente } \\
\text { conhecer as } \\
\text { experiências dos outros, } \\
\text { buscar treinamentos, } \\
\text { consultorias, melhorias } \\
\text { internas, e é isso que a } \\
\text { gente tá buscando } \\
\text { (Predecessor, Entrevista } \\
\text { 8). }\end{array}$ \\
\hline Crescimento & $\begin{array}{l}\text { As meninas contribuem } \\
\text { muito, contribuíram } \\
\text { muito pra empresa com } \\
\text { as mudanças que elas } \\
\text { vêm implementando. A } \\
\text { partir do momento que } \\
\text { foram acontecendo } \\
\text { essas mudanças, que a } \\
\text { gente foi adquirindo } \\
\text { essas experiências, } \\
\text { conhecendo um pouco } \\
\text { mais em profundidade } \\
\text { as suas teorias, os seus } \\
\text { resultados que foram } \\
\text { sendo conquistados, a } \\
\text { nossa empresa } \\
\text { começou a se } \\
\text { modernizar, começou a } \\
\text { crescer e começou a } \\
\text { ocupar cada vez mais } \\
\text { espaço dentro da nossa } \\
\text { cidade (Fundador, } \\
\text { Entrevista 2). }\end{array}$ & $\begin{array}{l}\text { Aí nós começamos a } \\
\text { entrar e começamos a } \\
\text { desenvolver a empresa } \\
\text { (...) com um objetivo de } \\
\text { crescimento, objetivo que } \\
\text { faltava no meu pai. Então, } \\
\text { eu pude desenvolver a } \\
\text { empresa, abri lojas e, } \\
\text { mesmo depois da } \\
\text { separação, a gente } \\
\text { continuou trabalhando } \\
\text { forte e crescendo a } \\
\text { [empresa] cada vez mais. } \\
\text { (Predecessor, Entrevista } \\
\text { 4). }\end{array}$ & $\begin{array}{l}\text { A evolução foi assim } \\
\text { bem grande (...) e essa } \\
\text { evolução foi em função } \\
\text { do investimento, das } \\
\text { mudanças e melhorias } \\
\text { que nós fizemos. (...) Eu } \\
\text { vejo que o crescimento } \\
\text { 'tá muito ligado a parte } \\
\text { da gestão. Então, nessa } \\
\text { parte de gestão, a gente } \\
\text { 'tá sempre buscando } \\
\text { melhorias, } \\
\text { acompanhando o que há } \\
\text { de novo no mercado, } \\
\text { fazendo melhorias na } \\
\text { área comercial, na área } \\
\text { financeira... } \\
\text { (Predecessor, Entrevista } \\
\text { 8). }\end{array}$ \\
\hline
\end{tabular}




\begin{tabular}{|c|c|c|c|}
\hline Competitividade & $\begin{array}{l}\text { (...). A partir do } \\
\text { momento em que nós } \\
\text { fomos adquirindo novos } \\
\text { conhecimentos (...), } \\
\text { fomos mudando a nossa } \\
\text { forma de agir e de } \\
\text { pensar, e fomos pondo } \\
\text { isso em prática, nós } \\
\text { fomos crescendo. A } \\
\text { gente foi vendo que nós } \\
\text { temos um domínio } \\
\text { quase absoluto do } \\
\text { mercado, uma liderança } \\
\text { quase que absoluta do } \\
\text { mercado. Nós fomos } \\
\text { ganhando o mercado } \\
\text { gradativamente e, hoje, } \\
\text { a nossa concorrência } \\
\text { está numa distância } \\
\text { imensurável nossa e } \\
\text { sem condições de nos } \\
\text { alcançar (Fundador, } \\
\text { Entrevista 1). }\end{array}$ & $\begin{array}{l}\text { Eu percebo que foi esse } \\
\text { nosso trabalho, a nossa } \\
\text { determinação, que fez a } \\
\text { gente chegar onde a gente } \\
\text { chegou. (...) Hoje, eu } \\
\text { posso te dizer que a } \\
\text { [empresa] tá na liderança } \\
\text { do mercado, não abriu } \\
\text { espaço pra concorrência } \\
\text { (Predecessor, Entrevista } \\
\text { 4). }\end{array}$ & $\begin{array}{l}\text { (...) A gente tem } \\
\text { sobressaído, não só aqui } \\
\text { na cidade, mas na } \\
\text { região. A venda nossa é } \\
\text { regional. (...) Se estamos } \\
\text { conseguindo atingir um } \\
\text { mercado regional, é } \\
\text { porque tem um } \\
\text { diferencial. Porque não é } \\
\text { só de produto: aí entra } \\
\text { produto, entra serviço, } \\
\text { etc. Tudo isso aí te ajuda } \\
\text { e te dá credibilidade. E } \\
\text { eu acho que agora que } \\
\text { nós estamos numa fase } \\
\text { muito boa, de uns anos } \\
\text { pra cá, que o comércio } \\
\text { foi incrementado, e } \\
\text { chegamos num domínio } \\
\text { regional do mercado de } \\
\text { material de construção } \\
\text { (Predecessor, Entrevista } \\
\text { 8) }\end{array}$ \\
\hline
\end{tabular}

A evolução de processos de sucessão em empresas familiares, entretanto, pode envolver perspectivas que assumem um caráter de descontinuidade. $O$ caso da empresa familiar do setor farmacêutico apresenta um elemento diferenciado, associado à configuração de conflitos entre sucessores membros da segunda geração da família empresária (Quadro 4).

\begin{tabular}{|l|l|}
\hline Elemento & \multicolumn{1}{c|}{ Caso 2 } \\
\hline \multirow{6}{*}{ Conflito } & $\begin{array}{l}\text { (...) Começou a dar umas divergências porque a gente sobressaia, a gente conseguia } \\
\text { fazer as coisas e eles não conseguiam (...). E, com isso, foi começando dar aquelas } \\
\text { divergências e eu mesmo sugeri: 'eu acho que você tem que sair daqui, porque não } \\
\text { 'tá dando certo'. (...) Então, o [predecessor] passou toda a sua parte na [matriz] para } \\
\text { os irmãos, sem ficar com nada (...) e a gente ficou só com a farmácia do centro. } \\
\text { Aquele foi um momento muito difícil. A briga deles obrigou a gente a fechar algumas } \\
\text { lojas e quase fez que a gente fechasse as portas, porque o dinheiro sumiu } \\
\text { (Predecessora, Entrevista 5). }\end{array}$ \\
$\begin{array}{l}\text { (...) depois de 92, [a empresa] já prosperou. De 92 para cá eu comprei esse prédio } \\
\text { todo aqui, (...) ampliei, comprei um monte de coisas. Mas o problema te ensina muita } \\
\text { coisa. Hoje, a gente num da moleza mais não (Predecessor, Entrevista 4). }\end{array}$ \\
\hline
\end{tabular}

Quadro 4 - Conflitos nas empresas familiares

No caso da empresa do setor farmacêutico, as divergências entre os sucessores influenciaram de forma negativa a qualidade das relações familiares, ao mesmo tempo em que modificaram de forma significativa a organização, levando-a a enfrentar dificuldades gerenciais, períodos de retração das atividades e de dificuldades financeiras, o que ocasionou a divisão da organização em dois grupos empresariais: de um lado, o grupo liderado pelo predecessor retomou a trajetória de 
crescimento, com a abertura de filiais e a ampliação dos negócios e do patrimônio da família; de outro, o grupo liderado pelos irmãos do predecessor ficou estagnado, não apresentando crescimento após a separação, fato que influencia negativamente suas perspectivas de continuidade futura.

Dependendo do encaminhamento desse processo e da qualidade das relações e interações entre indivíduos (predecessores e sucessores), família e empresa, há a possibilidade de que a sucessão não se concretize. Nesse sentido, a forma e a intensidade como esse conflito se revela pode impactar negativamente a empresa familiar e a família empresária, influenciando o processo de definição de objetivos e estratégias, as atividades gerenciais e operacionais internas, bem como a (in)efetividade do processo de sucessão como um todo, ou, em outros termos, resultando em uma não sucessão.

Paralelamente, o fenômeno do intraempreendedorismo também pode assumir perspectivas distintas no decorrer dos processos de sucessão, variando de acordo com a capacidade e liberdade para que os sucessores atuem de forma intraempreendedora. Com efeito, pode haver a manifestação de resistências à mudança no decorrer de tal processo (Quadro 5).

Quadro 5 - Resistência às mudanças efetuadas por sucessores

\begin{tabular}{|l|l|l|}
\hline Elemento & \multicolumn{1}{|c|}{ Caso 2 } & \multicolumn{1}{c|}{ Caso 3 } \\
\hline \multirow{5}{*}{ Resistência } & Ocorreu uma sucessão, mas, o papai & [Os jovens não têm medo de nada. E \\
& continuou na administração. (...) Tudo & querem fazer coisas que a gente tem \\
& que ele falava ainda era acatado, não & hora que breca. Teve uma reunião que \\
& podia fugir muito da regra não. A & nós fizemos com eles, que eles vieram \\
& gente tinha que fazer as coisas & com uma proposta enorme, de quanto \\
& escondido (...). Mas, a maioria das & que ficava pra abrir uma filial. Aí eu \\
& vezes ele não deixava fazer não. & pensei: 'numa época que tava mais difícil, \\
& Muita coisa a gente fazia escondido. & que tava custoso de dar conta, de achar \\
& Aí ele brigava, mas já 'tava feito, ele & gente pra trabalhar que tenha \\
& deixava isso pra lá. Mas, muitas & qualificação, nós ainda vamos abrir uma \\
& vezes, ele dava o contra, depois ele & filial, a gente não vai conseguir montar \\
& via que tava certo. Só dava o contra & um padrão de loja maior, que é o que a \\
& para poder manter mesmo a tradição & gente tem aqui hoje. Se fosse só os \\
& dele de chefe (Predecessor, & jovens aqui, eu acho que eles tinham \\
& Entrevista 4). & tentado, e poderiam ter até sucesso. Mas, \\
& & num caso desses, nem eu nem o meu \\
& cunhado não aprovou. Mas, isso não quer \\
& dizer que futuramente não tenha. Eu num \\
& tenho essa pretensão, mas acho que isso \\
& & aí é algo que cabe a eles decidir no \\
& futuro, depois que assumirem o nosso \\
& lugar... (Predecessora, Entrevista 9). \\
\hline
\end{tabular}


Desde o momento em que os sucessores assumem uma posição de liderança, eles passam a empreender ações de inovação e de criação de valor, conduzindo a empresa familiar ao crescimento e à competitividade. Eles podem, entretanto, sofrer resistências à suas ações e intervenções, pois os predecessores muitas vezes podem se posicionar de forma contrária à efetivação de mudanças, impedindo o desenvolvimento de novas atividades, de novos processos organizacionais e de criação de novas unidades da empresa familiar. Em outros termos, a ação empreendedora dos sucessores pode ser restringida pelos membros das gerações predecessoras, inibindo perspectivas atuais e futuras de expansão dos negócios, e convergindo para a possibilidade de não intraempreendedorismo.

\subsection{A RECONSTRUÇÃO DO PROCESSO DE SUCESSÃO EMPREENDEDORA EM EMPRESAS FAMILIARES}

Com a interação entre os campos de estudo sobre empreendedorismo e empresas familiares, surge a possibilidade de construção de perspectivas diferenciadas, que permitem revelar e compreender a dinâmica de fenômenos intraempreendedores que se manifestam no decorrer dos processos de sucessão.

Os elementos do processo de sucessão encontram-se articulados em uma perspectiva dinâmica, assumindo um caráter de construção da sucessão ao longo de diferentes gerações da família empresária e de diferentes trajetórias da empresa familiar. Nesse sentido, predecessores e sucessores passam a ser corresponsáveis pela construção dessa sucessão, na medida em que viabilizam a aceitabilidade, a credibilidade, a legitimidade, e a posterior liderança dos sucessores na empresa familiar. Com a aquisição dessa liderança, os sucessores passam a dispor de autonomia, assumindo uma atuação em termos estratégicos. Essa liderança também possibilita a continuidade da organização, por meio de ações que asseguram o legado da geração predecessora, além de possibilitar a agregação de novas atividades, práticas inovadoras e direcionamentos, os quais contribuem para a renovação da empresa familiar.

Associados ao processo sucessório podem ocorrer conflitos familiares e de resistências à mudança, revelando possíveis descontinuidades de processos de sucessão e de manifestação do intraempreendedorismo, podendo influenciar a forma como é conduzido o processo de sucessão empreendedora. Ou seja, ao gerar conflitos e divergências entre os membros familiares, e ao limitar a ação 
empreendedora dos sucessores, a família empresária acaba por impedir a construção de um processo de sucessão empreendedora, inviabilizando, no limite, as perspectivas de renovação e continuidade futura da empresa familiar.

A presença de elementos como o conflito e a resistência à mudança, contudo, nem sempre impedem a construção de processos de sucessão empreendedora. De fato, é o modo como conflitos e resistências são equacionados que determina a qualidade dos resultados obtidos com a sucessão. No momento em que os sucessores efetuam inovações, criam valor, contribuem para o crescimento e competitividade, eles passam a reunir as condições para permitir a construção efetiva de um processo de sucessão empreendedora. Torna-se necessária, pois, a reformulação do diagrama, incluindo e valorizando esses novos elementos que foram identificados por meio da análise dos casos.

O modelo originalmente proposto traz a marca da relação dialética entre transmissão gerencial e patrimonial, que constituem um todo dinâmico, e que envolve o reconhecimento constante, mutável, de um sentido subjetivo de controle (DE PONTET et al., 2007) por parte de sucessores e predecessores. A impulsão de empresas feita por sucessores envolve a manifestação do intraempreendedorismo, trazendo a marca de ações empreendedoras desses agentes. Neste sentido, o estudo multicaso permite verificar aspectos de uma vertente conjunta entre empreendedorismo e empresas familiares. Tais aspectos, em interação dinâmica, permitem analisar fatos de sucessão nessas organizações como sucessão empreendedora. A reconstrução do modelo envolve, entretanto, sua complementação pelo reconhecimento de dois caminhos alternativos, os quais traduzem as particularidades dessa relação dinâmica entre sucessão e intraempreendedorismo. São incluídas duas possibilidades de descontinuidade, a não sucessão e o não intraempreendedorismo, as quais constituem fatores restritivos para a consolidação de processos de sucessão empreendedora.

Com os elementos presentes no modelo reconstruído, é possível observar uma multiplicidade de eventos, situações e perspectivas que emergem e que se associam à natureza do processo de sucessão e do fenômeno do intraempreendedorismo. Com efeito, a noção de sucessão empreendedora passa a ser valorizada com essa construção, pois são os próprios agentes envolvidos que constroem a realidade identificada no decorrer do processo sucessório empreendedor. Essa construção pode envolver conflitos e resistências às 
mudanças, aspectos limitadores que a perpassam, evidenciando desafios para predecessores e sucessores, podendo levar, no limite, à não sucessão ou ao não intraempreendedorismo. A sucessão empreendedora se verificaria também na superação desses desafios que podem fazer parte de histórias de empresas familiares.

Cabe ressaltar, por fim, que a noção de sucessão empreendedora é aqui visualizada em uma perspectiva mais ampla, sob esta perspectiva da construção social. Tal visão se diferencia daquela exposta por autores como Davis (1968), Dyer Jr. e Handler (1994) e Woodfield (2007) que a definem como uma simples substituição do empreendedor/fundador enquanto elemento responsável pela direção, controle e condução dos negócios e atividades da empresa familiar. A reconstrução do modelo original (Figura 2) envolve, pois, a consideração dos elementos Não sucessão e Não intraempreendedorismo, cobrindo o espectro possível das situações envolvendo renovação e continuidade de empresas familiares. Sendo assim, a sucessão empreendedora é compreendida como um processo socialmente construído a partir da interação entre predecessores e sucessores, no qual se verifica a manifestação de ações intraempreendedoras de sucessores e que, quando feito de forma bem realizada, pode contribuir de modo significativo para a renovação e continuidade futura da empresa familiar.

Figura 2 - Reconstrução do processo de sucessão empreendedora em empresas familiares

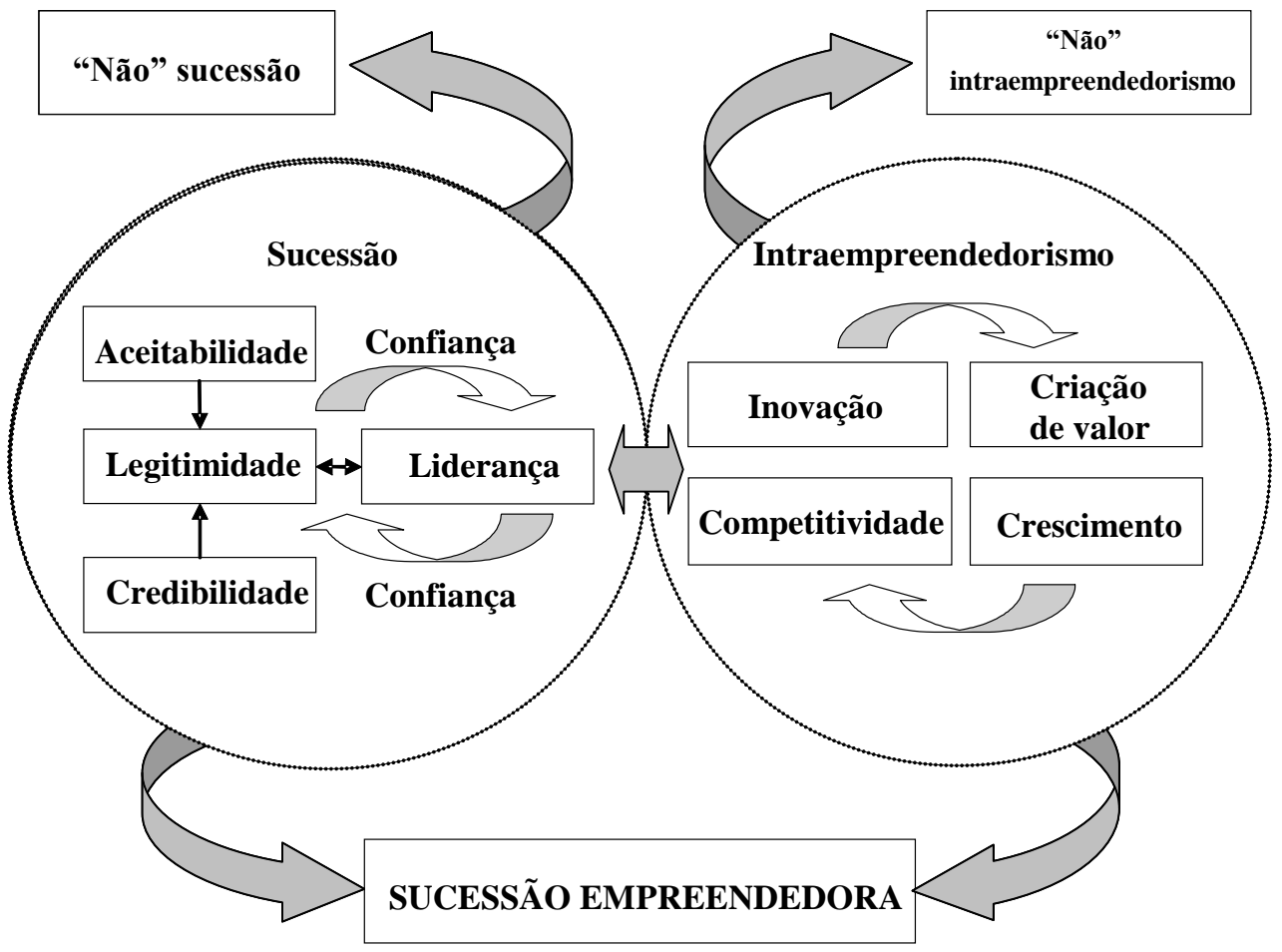




\section{CONSIDERAÇÕES FINAIS}

Neste trabalho, foi elaborada a noção de sucessão empreendedora, envolvendo elementos presentes no campo de estudos sobre empreendedorismo e no campo de estudos sobre empresas familiares.

A partir da proposta teórico-metodológica da pesquisa, foram reunidos elementos que permitem compreender a construção de processos de sucessão empreendedora em empresas familiares. Tais processos estão fundamentados na perspectiva da ação intraempreendedora de sucessores, ações essas que influenciam a sucessão na medida em que contribuem para a renovação e para a continuidade da empresa familiar. Assim, essa noção passa a assumir um caráter de construção social da sucessão, voltado para a perspectiva dos agentes que dela participam e que são responsáveis pela construção desse processo.

Desse modo, os elementos apresentados no modelo proposto constituem categorias que permitem a identificação e a verificação de processos de sucessão em empresas familiares, do fenômeno do intraempreendedorismo e da manifestação da ação intraempreendedora de sucessores. Essas categorias podem estar presentes na análise, indicando sua potencialidade de efeitos sobre continuidade e renovação de empresas familiares no decorrer e após a construção de processos de sucessão empreendedora.

Torna-se relevante, ainda, ressaltar o potencial analítico que a noção de sucessão empreendedora passa a assumir, tanto em termos teóricos como em termos analíticos. A elaboração do modelo foi resultado de um processo de construção teórica, mas também envolveu a reflexão e posterior reformulação, após evidências obtidas junto aos casos estudados. Assim, de forma consistente com a perspectiva teórico-metodológica, o quadro teórico assumiu um caráter de provisoriedade, convergindo para a evidência desse processo enquanto construção da sucessão empreendedora.

Ao possibilitar a verificação do processo de sucessão empreendedora, abrese espaço para a ampliação do horizonte de pesquisas sobre a problemática da sucessão em empresas familiares. Nesse sentido, torna-se necessário valorizar o potencial do modelo proposto e aprofundar a análise de seus elementos, bem como aprofundar a análise da interação entre o campo de estudos sobre empresas 
familiares e empreendedorismo. Com isso, será possível contribuir para o crescimento e o desenvolvimento teórico do campo de estudos sobre empresas familiares, permitindo o estabelecimento de novas direções de pesquisa e de novas alternativas para a compreensão dos diferentes aspectos associados à natureza específica dos processos de sucessão em empresas familiares.

\section{REFERÊNCIAS}

ANTONCIC, B.; HISRICH, R. Clarifying the intrapreneurship concept. Journal of Small Business and Enterprise Development, v. 10, n. 1, p. 7-24, feb. 2003.

BARDIN, L. Análise de conteúdo. 3. ed. Lisboa: Edições 70, 2004. 223 p.

BAYAD, M.; BARBOT, M. C. Proposition d'un modèle de succession dans les PME familiales: étude de cas exploratoire de relation père-fille. In: CONGRÈS

INTERNATIONAL FRANCOPHONE EN ENTREPRENEURIAT ET PME, AIREPME, 6., 2002, Montréal. Anais... Montreal: AIREPME, 2002.

BERGER, P.L.; LUCKMANN, T. A Construção social da realidade: tratado da sociologia do conhecimento. 25 ed. Petrópolis: Vozes, 2005. 274p.

BORGES, A. F.; LIMA, J. B.; CARVALHO, F. A. P. Interação entre indivíduos, família e empresa na construção do processo de sucessão em uma empresa familiar. In: ENCONTRO DA ASSOCIAÇÃO NACIONAL DE PÓS-GRADUAÇÃO E PESQUISA EM ADMINISTRAÇÃO, 32., 2008, Rio de Janeiro. Anais... Rio de Janeiro: ANPAD, 2008.

BROCKHAUS, R. Family business successions: suggestions for future research. Family Business Review, v. 17, n. 2, p. 165-177, jun 2004.

CARRIERI, A.P.; SARAIVA, L.A.S.; PIMENTEL, T.D. A institucionalização da feira hippie de Belo Horizonte. Organizações \& Sociedade, Salvador, v.15, n.44, p.6379, jan/mar 2008.

CRESWELL, J. W. Projeto de pesquisa: métodos qualitativo, quantitativo e misto. 2. ed. Porto Alegre: Artmed, 2007. 248 p.

DAVEL, E.; COLBARI, A. Organizações familiares: desafios, provocações e contribuições para a pesquisa organizacional. In: ENCONTRO DA ASSOCIAÇÃO NACIONAL DE PÓS-GRADUAÇÃO E PESQUISA EM ADMINISTRAÇÃO, 27., 2003, Atibaia. Anais... Atibaia: ANPAD, 2003. 
DAVEL, E.; COLBARI, A. Organizações familiares: por uma introdução à sua tradição, contemporaneidade e multidisciplinaridade. Organizações \& Sociedade, Salvador, v. 7, n. 18, p. 45-64, maio/ago. 2000.

DAVIS, S. M. Entrepreneurial succession. Administrative Science Quarterly, Ithaca, v. 13, n. 3, p. 402-416, dec. 1968.

DEBICKI, B. J.; MATHERNE III, C.F.; KELLERMANNS, F.W.; CHRISMAN, J.J. Family Business Research in the New Millennium: An Overview of the Who, the Where, the What, and the Why. Family Business Review, Thousand Oaks, v. 22, n.2, p.151-166, jun. 2009.

DONNELLEY, R. G. The family business. Harvard Business Review, v. 42, n. 4, p. 94-105, july/aug. 1964.

DYER JUNIOR, W. G.; HANDLER, W. Entrepreneurship and family business: exploring the connections. Entrepreneurship: Theory \& Practice, v. 19, n. 1, p. 7183, jan. 1994.

FLETCHER, D. Interpreneurship: organizational (re)emergence and entrepreneurial development in a second generation family firm. International Journal of Entrepreneurship Behaviour and Research, Bingley, v. 10, n. 1/2, p. 34-38, jan/apr. 2004.

GARCIA, U. L.; GIMENEZ, F. A. P.; TOLEDO, A. Ações e comportamento intraempreendedores: uma escala de mensuração. In: ENCONTRO DE ESTUDOS SOBRE EMPREENDEDORISMO E GESTÃO DE PEQUENAS EMPRESAS, 5. 2008, São Paulo. Anais... São Paulo: EGEPE, 2008.

GARTNER, W. B. What are we talking about when we talk about entrepreneurship? Journal of Business Venturing, v. 5, n. 1, p. 15-28, jan/feb. 1990.

GODOI, C. K.; BALSINI, C. P. V. A pesquisa qualitativa nos estudos organizacionais brasileiros: uma análise bibliométrica. In: GODOI, C. K.; BANDEIRA-DE-MELLO, R.; SILVA, A. B. da (Org.). Pesquisa qualitativa em estudos organizacionais: paradigmas, estratégias e métodos. São Paulo: Saraiva, 2006. p. 89-112.

GODOI, C. K.; MATTOS, P. L. C. L. de. Entrevista qualitativa: instrumento de pesquisa e evento dialógico. In: GODOI, C. K.; BANDEIRA-DE-MELLO, R.; SILVA, A. B. da (Org.). Pesquisa qualitativa em estudos organizacionais: paradigmas, estratégias e métodos. São Paulo: Saraiva, 2006. p. 303-323.

GODOY, A. S. Estudo de caso qualitativo. In: GODOI, C. K.; BANDEIRA-DEMELLO, R.; SILVA, A. B. da (Org.). Pesquisa qualitativa em estudos organizacionais: paradigmas, estratégias e métodos. São Paulo: Saraiva, 2006. p. 89-112. 
GRZYBOVSKI, D.; HOFFMANN, P. Z.; MUHL, E. E. Estratégia e sucessão na gestão de empresas familiares: um estudo do caso Gerdau. In: ENCONTRO DE ESTUDOS ORGANIZACIONAIS, 5., 2008, Belo Horizonte. Anais... Belo Horizonte: ANPAD, 2008.

HAVEMAN, H. A.; KHAIRE, M. V. Survival beyond succession?: the contingent impact of founder succession on organizational failure. Journal of Business

Venturing, Saint Louis, v. 19, n. 3, p. 437-463, may. 2004.

HECK, R. K. Z.; et al. Emerging paths of family entrepreneurship research. Journal of Small Business Management, v. 46, n. 3, p. 317-330, july. 2008.

HECK, R. K. Z.; et al. The family's dynamic role within family business entrepreneurship. In: POUTZIOURIS, P. Z.; SMYRNIOS, K. X.; KLEIN, S. B. (Org.). Handbook of research on family business. Cheltenham: E.Elgar, 2006. p. 80-105.

HECK, R. K. Z.; MISHRA, C. S. Family entrepreneurship. Journal of Small Business Management, v. 46, n. 3, p. 313-316, july. 2008.

IBRAHIM, A. B.; SOUFANI, K.; POUTZIOURIS, P.; LAM, J. Qualities of an effective successor: the role of education and training. Education \& Training, v. 46, n. 8/9, p. 474-491, nov/dec. 2004.

KELLERMANNS, F. W.; EDDLESTON, K. A. Corporate entrepreneurship in family firms: a family perspective. Entrepreneurship: Theory \& Practice, Boca Raton, v. 30, n. 6, p. 809-830, nov. 2006.

LAMBRECHT, J. Multigenerational transition in family businesses: a new explanatory model. Family Business Review, v. 18, n. 4, p. 267-282, dec. 2005.

LIMA, J.B. Ações Empreendedoras e Práticas de Pesquisa em Empreendedorismo. In: COLÓQUIO SOBRE EMPREENDEDORISMO E ESTRATÉGIA DE EMPRESAS DE PEQUENO PORTE, 1., 2008, Curitiba. Anais... Curitiba: PUC-PR, 2008.

LIMA, J. B.; BORGES, A. F.; CARVALHO, F. A. P. Construção do processo de sucessão em empresas familiares: transmissão gerencial e patrimonial. In: ENCONTRO DA ASSOCIAÇÃO NACIONAL DE PÓS-GRADUAÇÃO E PESQUISA EM ADMINISTRAÇÃO, 31., 2007, Rio de Janeiro. Anais... Rio de Janeiro: ANPAD, 2007.

MATTOS, P. L. C. L. de. Análise de entrevistas não estruturadas: da formalização à pragmática da linguagem. In: GODOI, C. K.; BANDEIRA-DE-MELLO, R.; SILVA, A. B. da (Org.). Pesquisa qualitativa em estudos organizacionais: paradigmas, estratégias e métodos. São Paulo: Saraiva, 2006. p. 347-373. 
MELO, M. C. O. L.; OLIVEIRA, M. C. S. M.; PAIVA, K. C. M. Produção Científica Brasileira sobre Empresa Familiar: um metaestudo de artigos publicados em anais de eventos da ANPAD no período de 1997-2007. Revista de Administração Mackenzie, São Paulo, v.9, n.6, p.148-173, out/dez. 2008.

OLIVEIRA, J. B.; FILION, L. J.; CHIRITA, M. G. Estudo das linhas sobre os intraempreendedores e organização empreendedora: exame da documentação de 1996 a 2006. In: ENCONTRO DE ESTUDOS SOBRE EMPREENDEDORISMO E GESTÃO DE PEQUENAS EMPRESAS, 5., 2008, São Paulo. Anais... São Paulo: EGEPE, 2008.

PONTET de; WROSCH, C.; GAGNE, M. An exploration of generational differences in levels of control held among family business approach sucession, Family Business Review, Boston, v. 20, n. 4, p. 337-354, dec. 2007.

ROESCH, S. M. A. Projetos de estágio e de pesquisa em administração. 3. ed. São Paulo: Atlas, 2006. 312 p.

SHARMA, P. An overview of the field of family business studies: current status and directions for the future. In: POUTZIOURIS, P. Z.; SMYRNIOS, K. X.; KLEIN, S. B. (Org.). Handbook of research on family business. Cheltenham: E.Elgar, 2006. p. 25-55.

SHARMA, P.; CHRISMAN, J. J. Toward a reconciliation of the definitional issues in the field of corporate entrepreneurship. Entrepreneurship: Theory \& Practice, v. 23, n. 3, p. 11-27, aug. 1999.

SHARMA, P.; CHRISMAN, J. J.; CHUA, J. H. Strategic management of the family business: past research and future possibilities. Family Business Review, v.10, n.1, p.1-36, mar. 1997.

TILLMANN, C.; GRZYBOVSKI, D. Sucessão de dirigentes na empresa familiar: estratégias observadas na família empresária. Organizações \& Sociedade, Salvador, v. 12, n. 32, p. 45-61, jan/mar. 2005.

YIN, R. K. Estudo de caso: planejamento e métodos. 3. ed. Porto Alegre: Bookman, 2005. $212 \mathrm{p}$.

WOODFIELD, P. Intergenerational entrepreneurship in family business.

Auckland: University of Auckland, 2007. 14p. Disponível em:

$<$ https://intellagence.eu.com/bin/

pdfabstract?dir=agse2008\&ref=47>. Acesso em: 27 mar. 2008. 